\title{
CULTIVO DE Escherichia coli RECOMBINANTE EM BIORREATOR AIRLIFT PRESSURIZADO
}

\author{
G. CAMPANI ${ }^{1}$, G. G. SILVA ${ }^{1}$, J. H. BONOMO ${ }^{1}$, J. V. L. ANDRADE ${ }^{1}$, M. M. JESUS ${ }^{1}$, C. B. \\ BORGES $^{1}$, A. C. L. HORTA ${ }^{1}$, R. C. GIORDANO ${ }^{1}$, A. C. BADINO ${ }^{1}$ e T. C. ZANGIROLAMI $^{1}$ \\ ${ }^{1}$ Programa de Pós-Graduação em Engenharia Química, Universidade Federal de São Carlos \\ E-mail para contato: gilson.campani@yahoo.com
}

\begin{abstract}
RESUMO - Diversas proteínas são produzidas em Escherichia coli recombinante empregando reatores convencionais (tanque agitado e aerado), mas há poucos estudos envolvendo o biorreator airlift, cujas vantagens são: menor complexidade de construção, baixo risco de contaminação e maior eficiência energética na transferência de oxigênio. Devido ao alto consumo de oxigênio característico dessa bactéria, a operação em sobrepressão se apresenta como um recurso para compensar a menor transferência de oxigênio no biorreator airlift. Nesse contexto, objetivou-se avaliar a influência da pressão, dentre outras variáveis, sobre as produtividades de biomassa e da proteína recombinante (PspA). Os experimentos foram conduzidos em biorreator airlift de cilindros concêntricos $(5 \mathrm{~L})$ equipado com controle automático de pressão, $\mathrm{pH}$, temperatura e concentração de oxigênio dissolvido. A pressurização do reator $(2,5$ bar) possibilitou alcançar valores de produtividade em biomassa e em proteína recombinante de até $1,27 \pm 0,06 \mathrm{gMS} / \mathrm{L} . \mathrm{h}$ e $201 \pm 8 \mathrm{mgPspA} / \mathrm{gMS}$, respectivamente. Os resultados obtidos comprovam o efeito positivo da pressão sobre a transferência de oxigênio.
\end{abstract}

\section{INTRODUÇÃO}

Avanços nas áreas de microbiologia e biologia molecular trouxeram, nas últimas quatro décadas, grandes melhorias nos bioprocessos, em especial nas indústrias de biotecnologia, acarretando em aumentos de produtividade e de qualidade dos produtos (Vojinovic et al., 2006). Como consequência, desde então, há um crescente número de produtos biotecnológicos sendo lançados e comercializados como, por exemplo, nas áreas farmacêutica, de alimentos e de energia (Vojinovic et al., 2006). Nesse contexto, a Escherichia coli é um dos microrganismos mais utilizados para a produção de proteínas heterólogas, uma vez que há ampla caracterização metabólica e genética deste organismo e métodos precisos e rápidos para a modificação de seu genoma (Demain e Vaishnav, 2009).

Com relação aos tipos de reatores utilizados em cultivos de E. coli, os estudos encontrados na literatura empregam, quase que exclusivamente, biorreatores convencionais (tanque agitado e aerado) (Korz et al., 1995; Shiloach e Fass, 2005; Horta, 2011; Santos, 2012; Silva et al., 2013). Mais recentemente, alguns estudos têm abordado o desenvolvimento de reatores não convencionais, tal como do tipo rocking motion (Glazyrina et al., 2010). Porém, cultivos de E. coli em reatores pneumáticos, em especial o biorreator airlift, que encontra grande aplicação industrial, têm sido pouco estudados (Kracke-Helmet et al., 1991; Janardhan et al., 2007), evidenciando um 
amplo campo de pesquisa a ser explorado.

Nesse cenário, o presente trabalho teve como objetivos estudar o cultivo em batelada de $E$. coli em biorreator airlift de circulação interna adaptado para operação em sobrepressão, avaliandose o efeito da pressão e de outras variáveis do processo sobre as produtividades de biomassa e da proteína recombinante (PspA).

\section{MATERIAIS E MÉTODOS}

\subsection{Microrganismo, Meio de Cultura e Biorreator}

Foi cultivado o bacilo gram-negativo Escherichia coli BL21(DE3)pET37b+/PspA4Pro, que expressa um fragmento da proteína imunogênica PspA (PspA4Pro) presente na parede celular do procarioto Streptococcus pneumoniae. Esta construção foi obtida no Laboratório de Biologia Molecular do Instituto Butantan pela pesquisadora Dra. Eliane N. Miyaji. O plasmídeo pET37b+ contém o promotor T7 (induzido por IPTG ou lactose) e gene de resistência à canamicina.

Para a realização dos cultivos no biorreator, foi utilizado meio de cultivo complexo de autoindução (Studier, 2005) adaptado por Santos (2012), contendo glicose (10 g/L) e glicerol (60 $\mathrm{g} / \mathrm{L})$ como fontes de carbono; Phytone $(10 \mathrm{~g} / \mathrm{L})$ e extrato de levedura $(5 \mathrm{~g} / \mathrm{L})$ como fontes de nitrogênio; lactose $(20 \mathrm{~g} / \mathrm{L})$ como indutor da expressão da proteína recombinante; tiamina (45 $\mathrm{mg} / \mathrm{L})$, canamicina $(100 \mathrm{mg} / \mathrm{L})$, propilenoglicol $30 \% \mathrm{v} / \mathrm{v}(1 \mathrm{~mL} / \mathrm{L})$ e sais diversos. Para a preparação das pré-culturas (inóculo e pré-inóculo), a composição do meio de cultura foi a mesma utilizada no cultivo em biorreator, com exceção da glicose $(0,5 \mathrm{~g} / \mathrm{L})$, do glicerol $(5 \mathrm{~g} / \mathrm{L})$ e da lactose (ausente). Todos os componentes foram previamente esterilizados por autoclavagem ou filtração (poro de $0,2 \mu \mathrm{m}$ ).

Os ensaios foram realizados em biorreator encamisado airlift de cilindros concêntricos de 5 L de volume útil (Badino et al., 2004) dotado de controle automático de $\mathrm{pH}$, temperatura, concentração de oxigênio dissolvido (COD) (Campani et al., 2013) e pressão, dentre outras funcionalidades.

\subsection{Métodos Analíticos}

O crescimento celular foi avaliado através da absorbância em espectrofotômetro a 600 $\mathrm{nm}\left(\mathrm{DO}_{600 \mathrm{~nm}}\right)$ e por meio da medida de massa seca $-\mathrm{C}_{\mathrm{x}}(\mathrm{gMS} / \mathrm{L})-$. A partir dos valores de $\mathrm{C}_{\mathrm{x}}$, calculou-se a produtividade de biomassa $-\mathrm{P}_{\mathrm{x}}(\mathrm{gMS} / \mathrm{L} . \mathrm{h})$.

Concentrações de glicerol, lactose, glicose e metabólitos (ácidos acético, lático e fórmico) foram determinadas por HPLC (sistema Waters Co; bombas HPLC 510, injetor W717, refratômetro W410 e leitor de UV PDA W996) utilizando a coluna Aminex HPX-87H (Bio-Rad) como fase estacionária e uma solução de $\mathrm{H}_{2} \mathrm{SO}_{4} 5 \mathrm{mM}$ como fase móvel, a uma vazão de $0,6 \mathrm{~L} / \mathrm{min}$ a $50^{\circ} \mathrm{C}$.

A estabilidade do plasmídeo foi estimada através do repique de unidades formadoras de colônia em meio sólido LB-ágar com e sem antibiótico (100 mg/L de canamicina) e a produção de proteína quantificada por SDS-PAGE e densitometria de banda (Campani, 2014). A partir de cada valor estimado para a concentração de PspA solúvel $\left(\mathrm{C}_{\mathrm{PspA}}\right)$, foi possível 
calcular a produção específica $-\mathrm{Y}_{\mathrm{PspA} / \mathrm{X}}(\mathrm{mgPspA} / \mathrm{gMS})-$ e a produtividade $-\mathrm{P}_{\mathrm{PspA}}$ (mgPspA/L.h) -, ambas de PspA solúvel.

O comportamento reológico do caldo foi avaliado durante a fase de indução do cultivo de E. coli no biorreator airlift pressurizado utilizando reômetro de cilindros concêntricos (Brookfield®, modelo DC-III+). Através de regressão não linear pelo método dos mínimos quadrados (Marquardt, 1963), o modelo descrito pela lei das potências (Equação 1) foi ajustado aos dados de velocidade de cisalhamento $(\dot{\gamma})$ e tensão de cisalhamento $(\tau)$ medidos. Com isso, foram obtidos os valores dos índices de escoamento (n) e de consistência (K) para cada amostra. Finalmente, através da Equação 2 e dos índices estimados, foi calculado $\mu_{\text {ap }}$ adotando $\dot{\gamma}$ correspondente à condição de operação do biorreator.

$$
\begin{aligned}
& \tau=K \cdot \dot{\gamma}^{n} \\
& \mu_{a p}=K \cdot \dot{\gamma}^{n-1}
\end{aligned}
$$

A fim de complementar a análise reológica, foi realizado o acompanhamento da morfologia celular em microscópio ótico (Olympus ${ }^{\circledR}$, modelo BX50) utilizando amostras do caldo retiradas no decorrer do cultivo e tratadas pelo método de Gram (Kyle et al., 2012). As imagens das lâminas bacteriológicas foram obtidas sob uma ampliação de 400 vezes através de sistema acoplado de aquisição digital de imagens.

\subsection{Procedimento Experimental}

Para a realização dos cultivos, uma suspensão de células de $E$. coli BL21(DE3)pET37b+/PspA4Pro estocadas a $-80{ }^{\circ} \mathrm{C}$ com $10 \% \mathrm{v} / \mathrm{v}$ de glicerol foi inicialmente estriada em placa de Petri com LB-ágar e $100 \mathrm{mg} / \mathrm{L}$ de canamicina. Em seguida, a placa foi incubada por $24 \mathrm{~h}$ a $37^{\circ} \mathrm{C}$, sendo, então, transferida uma colônia para o pré-inóculo (erlenmeyer estéril de $500 \mathrm{~mL}$ contendo $30 \mathrm{~mL}$ de meio de cultura). Este foi incubado em câmara rotativa a $270 \mathrm{rpm}$ e $37^{\circ} \mathrm{C}$ por cerca de $5 \mathrm{~h}$ até uma $\mathrm{DO}_{600 \mathrm{~nm}}$ próxima de 2,5 . O cultivo do inóculo foi iniciado com a adição de $5 \mathrm{~mL}$ do pré-inóculo em cada um dos três erlenmeyers estéreis de $500 \mathrm{~mL}$ contendo $100 \mathrm{~mL}$ de meio de cultura. A suspensão foi incubada a $270 \mathrm{rpm}$ e $37^{\circ} \mathrm{C}$ por cerca de $4 \mathrm{~h}$ até uma $\mathrm{DO}_{600 \mathrm{~nm}}$ próxima de 2,5 , quando foi transferido todo o volume do inóculo $(0,3 \mathrm{~L})$ para o biorreator airlift, dando início ao cultivo.

As condições de cultivo empregadas foram: temperatura inicial de $31{ }^{\circ} \mathrm{C}$ (reduzida progressivamente), $\mathrm{pH}$ de 6,7 (fase crescimento) e 6,9 (fase de indução) controlado através da adição de $\mathrm{NH}_{4} \mathrm{OH}$ ou $\mathrm{HCl}$, pressão absoluta de até 2,5 bar e COD entre 20 e $50 \%$ de saturação (ar à pressão atmosférica e $31^{\circ} \mathrm{C}$ ).

Amostras foram retiradas ao longo dos experimentos para a determinação de densidade ótica, estabilidade do plasmídeo, reologia, morfologia e concentrações de biomassa, metabólitos, açúcares e da proteína de interesse.

\section{RESULTADOS E DISCUSSÃO}

Dois cultivos de E. coli foram realizados no biorreator airlift, sendo um experimento de referência, conduzido sob pressão atmosférica, e o outro em sobrepressão. 


\subsection{Ensaio em Biorreator Airlift sem Pressurização}

No cultivo de E. coli de referência (sem pressurização), obteve-se o perfil de crescimento celular apresentado na Figura 1, com $\mathrm{C}_{\mathrm{x}}$ inicial de 0,16 $\pm 0,01 \mathrm{gMS} / \mathrm{L}$ e final de $20 \pm 1 \mathrm{gMS} / \mathrm{L}$, após $35 \mathrm{~h}$, quando o cultivo foi interrompido devido à insuficiência do fornecimento de oxigênio para o caldo de cultivo frente à alta demanda celular, obtendo-se $\mathrm{P}_{\mathrm{x}}$ de 0,57 \pm 0,03 gMS/L.h. Essa produtividade é bastante inferior à alcançada em biorreator convencional (tanque agitado e aerado), de 2,3 \pm 0,1 gMS/L.h, relatada por Santos (2012) para o mesmo microrganismo. A explicação para o baixo valor de $\mathrm{P}_{\mathrm{x}}$ obtido no biorreator airlift é o crescimento celular mais lento em virtude das baixas temperaturas empregadas (mínima de $15^{\circ} \mathrm{C}$ ). A redução gradual de temperatura até $15^{\circ} \mathrm{C}$ a partir de $12 \mathrm{~h}$ de cultivo $(3 \mathrm{~h}$ antes do início da fase de indução) foi um recurso adicional empregado nesse experimento na tentativa de manter a COD nos níveis desejados através da redução da demanda celular por oxigênio. Quanto à formação de metabólitos, verificou-se um baixo acúmulo de ácidos orgânicos (ácidos lático, fórmico e acético), todos abaixo de $1,5 \mathrm{~g} / \mathrm{L}$, indicando o correto balanceamento dos nutrientes presentes no meio de cultivo e a ausência de metabolismo fermentativo, ou seja, o fornecimento adequado de oxigênio para as células.

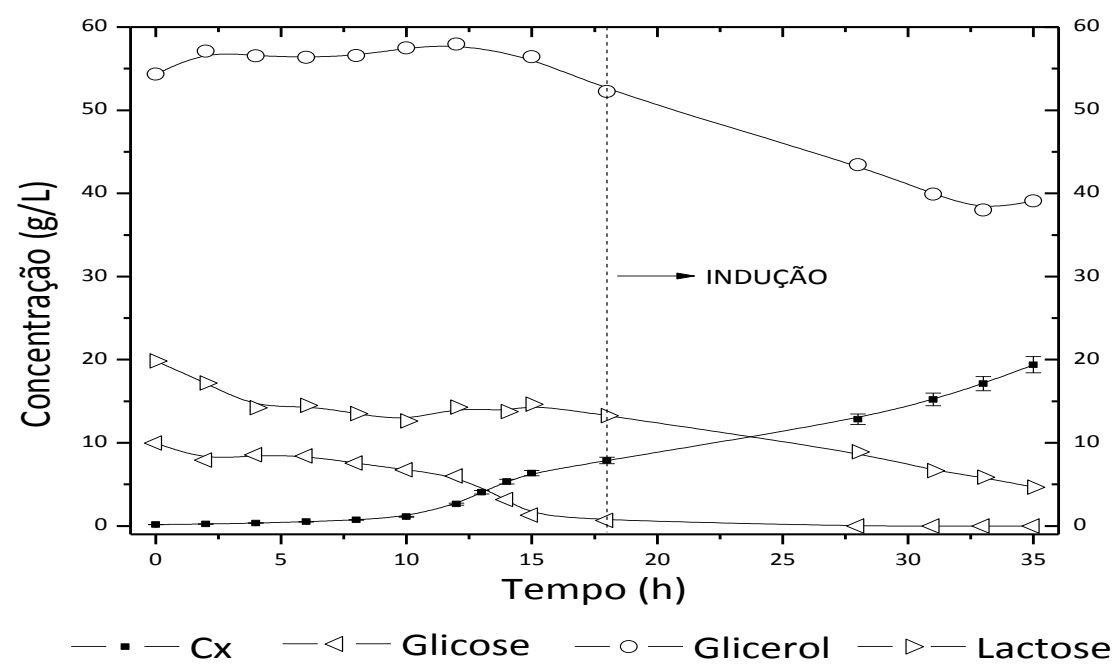

Figura 1 - Concentrações de biomassa $\left(\mathrm{C}_{\mathrm{x}}\right)$, glicose, glicerol e lactose ao longo do cultivo em batelada de E. coli em biorreator airlift. As barras de desvio padrão apresentadas se referem a medidas de $\mathrm{C}_{\mathrm{x}}$ em triplicata.

A fase de indução, com duração de $17 \mathrm{~h}$, teve início com o esgotamento da glicose em $18 \mathrm{~h}$ de cultivo, quando começou o consumo mais intenso da lactose e do glicerol, conforme destacado na Figura 1. O $\mathrm{Y}_{\mathrm{PspA} / \mathrm{X}}$ foi de $47 \pm 1 \mathrm{mgPspA} / \mathrm{gMS}$, sendo bastante inferior àquele alcançado em biorreator convencional (Santos, 2012), de $239 \pm 7$ mgPspA/gMS. Possivelmente, essa baixa produção de PspA solúvel se deve à reduzida atividade metabólica das células nas baixas temperaturas empregadas durante a indução (inferiores a $20^{\circ} \mathrm{C}$ ), o que naturalmente também resulta em menor velocidade de síntese da proteína recombinante. Esse fato já havia sido constatado por Santos (2012) em cultivo conduzido a $25^{\circ} \mathrm{C}$, no qual o $\mathrm{Y}_{\mathrm{PspA} / \mathrm{X}}$ foi $50 \%$ inferior ao observado a $31^{\circ} \mathrm{C}$. Como consequência da menor produção de proteína, do reduzido acúmulo de biomassa e do elevado tempo total de cultivo $(35 \mathrm{~h}$, ao 
invés das 17 h necessárias em biorreator convencional), o $\mathrm{P}_{\mathrm{PspA}}$ obtido (27 $\left.\pm 2 \mathrm{mgPspA} / \mathrm{L} . \mathrm{h}\right)$ foi significativamente inferior ao alcançado em biorreator convencional $(550 \pm 40$ mgPspA/L.h). A estabilidade plasmidial se manteve elevada durante a fase de indução, sendo superior a $90 \%$, indicando um baixo estresse metabólico nas células.

\subsection{Ensaio em Biorreator Airlift Pressurizado}

Através do cultivo de E. coli no biorreator airlift operado sob pressurização, atingiu-se, a partir de um $\mathrm{C}_{\mathrm{x}}$ inicial de 0,106 $\pm 0,006 \mathrm{gMS} / \mathrm{L}$, um $\mathrm{C}_{\mathrm{x}}$ final de $30 \pm 2 \mathrm{gMS} / \mathrm{L}$, após 23,5 h de cultivo (Figura 2). $\mathrm{O}$ valor final de $\mathrm{P}_{\mathrm{x}}$ foi de 1,27 $\pm 0,06 \mathrm{gMS} / \mathrm{L} . \mathrm{h}$, que é superior ao alcançado no airlift sem pressurização $(0,57 \pm 0,03$ gMS/L.h), mas inferior ao obtido no biorreator convencional (2,3 $\pm 0,1 \mathrm{gMS} / \mathrm{L} . \mathrm{h})$ (Santos, 2012). A explicação para isso se deve à temperatura mínima empregada durante o cultivo no biorreator airlift pressurizado, de $26^{\circ} \mathrm{C}$. Essa redução da temperatura acarretou em menor $\mathrm{P}_{\mathrm{x}}$ em relação ao cultivo controle em reator convencional à $31^{\circ} \mathrm{C}$ (Santos, 2012). Entretanto, em relação ao ensaio em biorreator airlift sem pressurização, o maior $\mathrm{P}_{\mathrm{x}}$ se deve à menor redução da temperatura, de 31 para $26^{\circ} \mathrm{C}$ no airlift pressurizado, ao invés da redução de 31 para $15^{\circ} \mathrm{C}$ no ensaio sem pressurização. A estratégia de controle da COD adotada foi sequencial (Figura 2), manipulando primeiramente a vazão de ar (QAR), seguida pela pressão, vazão de oxigênio puro (QO2) e, finalmente, a temperatura, possibilitando uma menor utilização de oxigênio puro, bem como uma redução menos drástica da temperatura. Com o aumento da pressão, foi preciso elevar a vazão mássica de gás, de acordo com a lei dos gases ideais, a fim de manter a vazão volumétrica do gás constante dentro do biorreator. As baixas concentrações acumuladas dos ácidos lático, fórmico e acético, com valores abaixo de $0,7 \mathrm{~g} / \mathrm{L}$, refletem a efetividade do sistema de controle da COD adotado.
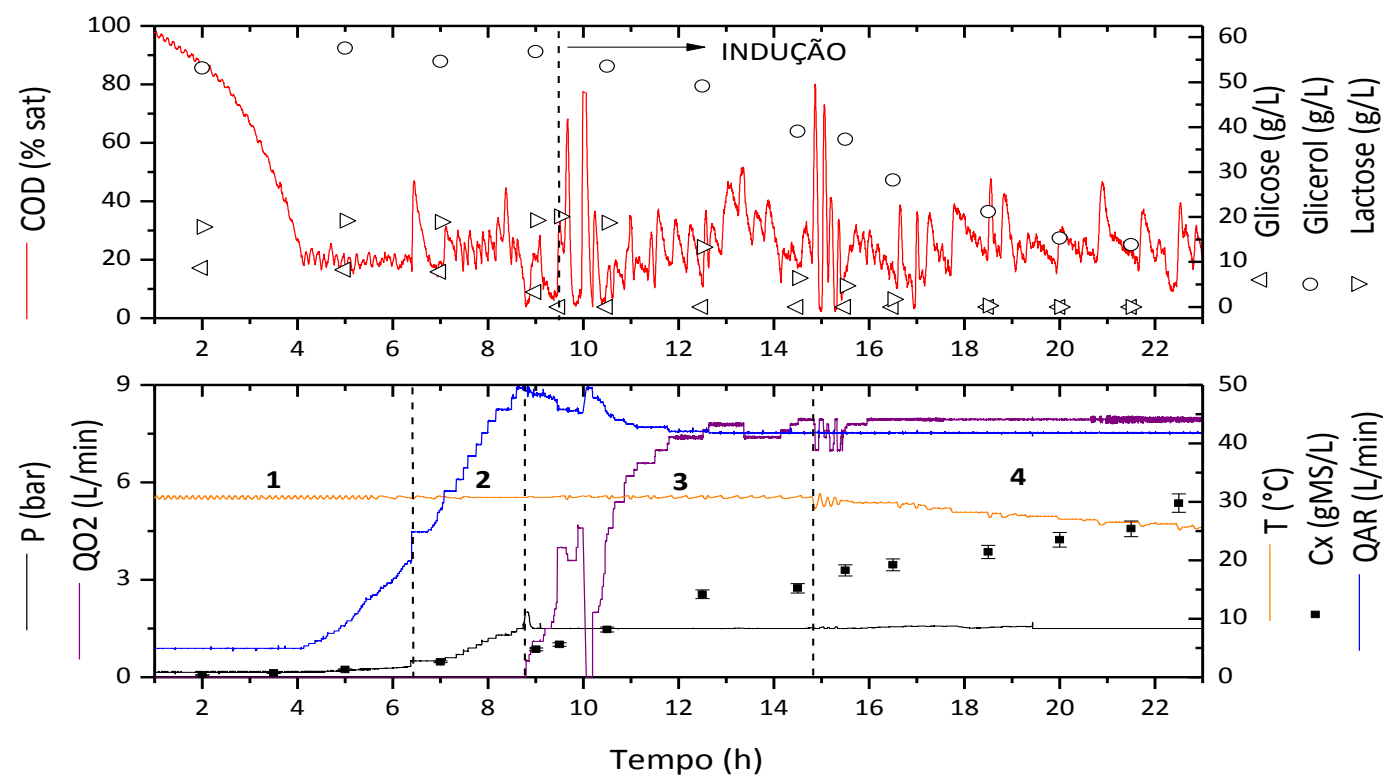

Figura 2 - Concentrações de biomassa $\left(\mathrm{C}_{\mathrm{x}}\right)$, glicose, glicerol e lactose e perfil de resposta da

COD com respeito à manipulação de QAR (Etapa 1), pressão (Etapa 2), QO2 (Etapa 3) e temperatura (Etapa 4) no cultivo em batelada de E. coli em biorreator airlift pressurizado. Os valores de QAR e QO2 apresentados são relativos à condição padrão de 1 atm e $21,1^{\circ} \mathrm{C}$. As

barras de desvio padrão apresentadas se referem a medidas em triplicata. 


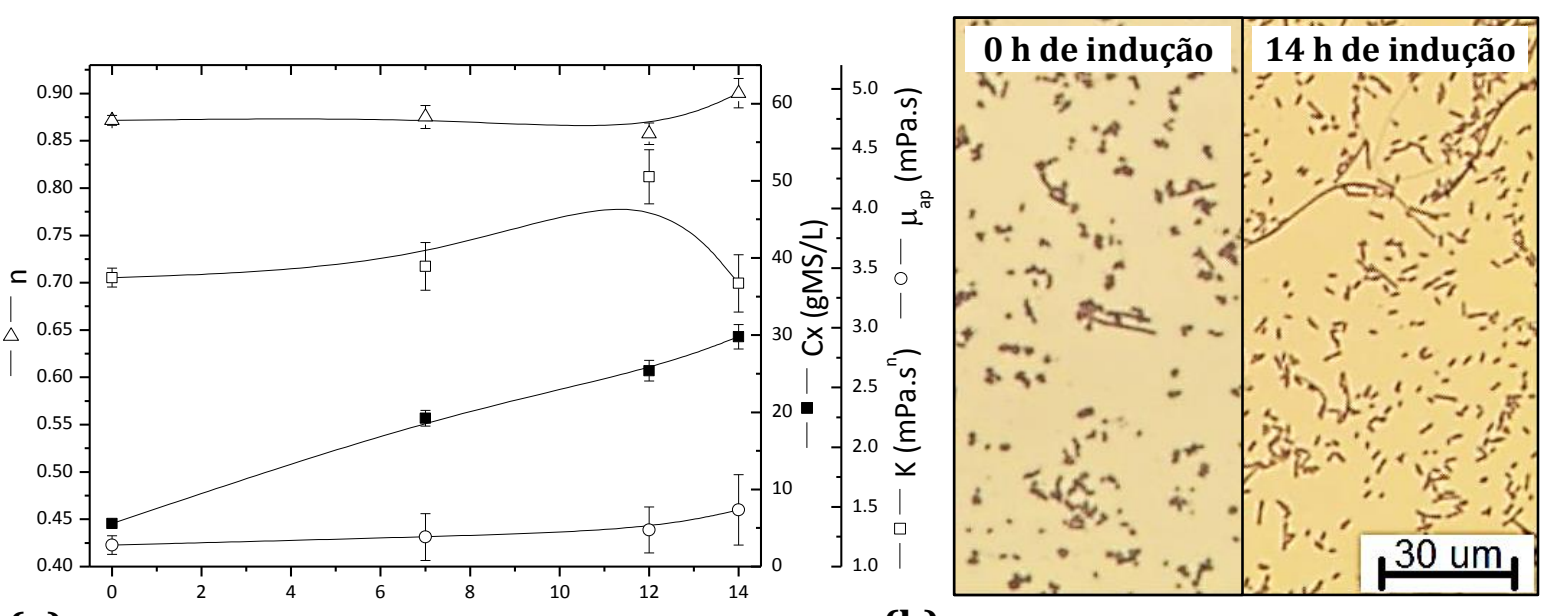

(a)

Tempo de indução (h)

(b)

Figura 3 - (a) $C_{x}$, acompanhamento reológico (n, $K$ e $\mu_{\mathrm{ap}}$ ) e (b) imagens de microscopia ótica (ampliação de 400x) de amostras retiradas ao longo da fase de indução do cultivo em batelada de E. coli em biorreator airlift pressurizado. As barras de desvio se referem ao desvio padrão das medidas em triplicata de $C_{x}$ e ao erro padrão das estimativas de $n, K$ e $\mu_{\text {ap }}$.

Por outro lado, a retenção do plasmídeo caiu de $87 \%$ no tempo $0 \mathrm{~h}$ de indução para $48,1 \%$ no fim da fase de indução, após $14 \mathrm{~h}$. Essa menor estabilidade plasmidial, em relação à alcançada no cultivo em biorreator airlift sem sobrepressão (superior a 90\%), reflete o estresse metabólico celular decorrente da superexpressão da proteína recombinante (PspA) pelas células. De fato, o $\mathrm{Y}_{\mathrm{PspA} / \mathrm{X}}$ máximo obtido no biorreator airlift pressurizado, após $12 \mathrm{~h}$ de indução, foi bastante superior, de $201 \pm 8 \mathrm{mgPspA} / \mathrm{gMS}$ contra $47 \pm 1 \mathrm{mgPspA} / \mathrm{gMS}$ alcançado no biorreator airlift sem pressurização, ou seja, um aumento de 4,3 vezes. Esse valor de $201 \pm 8 \mathrm{mgPspA} / \mathrm{gMS}$ está próximo ao obtido no ensaio controle em reator convencional à $31^{\circ} \mathrm{C}(239 \pm 7 \mathrm{mgPspA} / \mathrm{gMS})$ (Santos, 2012). Novamente, como ocorrido com $\mathrm{P}_{\mathrm{x}}$, a redução da temperatura para um valor intermediário $\left(26^{\circ} \mathrm{C}\right)$ entre a redução efetuada no biorreator airlift sem pressurização (para $15^{\circ} \mathrm{C}$ ) e a temperatura empregada no reator convencional $\left(31^{\circ} \mathrm{C}\right)$ explicam esses resultados de $\mathrm{Y}_{\mathrm{PspA} / \mathrm{X}}$. Como consequência dos valores de $\mathrm{P}_{\mathrm{x}}$ e $\mathrm{Y}_{\mathrm{PspA} / \mathrm{X}}$ alcançados no biorreator airlift pressurizado, obteve-se um $\mathrm{P}_{\mathrm{PspA}}(260 \pm 20$ mgPspA/L.h) intermediário entre o atingido no airlift sem pressurização ( $27 \pm 2 \mathrm{mgPspA} / \mathrm{L} . \mathrm{h}$ ) e no reator convencional (550 $\pm 40 \mathrm{mgPspA} / \mathrm{L} . \mathrm{h})$ (Santos, 2012).

Neste ensaio, foi feito também um acompanhamento da reologia do caldo de cultivo e da morfologia das células ao longo da fase de indução. $\mathrm{O}$ fluido apresentou comportamento não Newtoniano do tipo pseudoplástico $(n<1)$, com os valores de $n$, $K$ e $\mu_{\text {ap }}$ mostrados na Figura 3. As estimativas de $\mu_{\text {ap }}$ foram baseadas em $\dot{\gamma}$ médio de $4000 \mathrm{~s}^{-1}$, valor alcançado no biorreator airlift de cilindros concêntricos $(5 \mathrm{~L})$ operado com fluido não Newtoniano $\left(\mathrm{K}=0,180 \mathrm{~Pa} . \mathrm{s}^{\mathrm{n}}\right.$ e $\left.\mathrm{n}=0,461\right)$ e vazão de gás de $21 \mathrm{~L} / \mathrm{min}$ (Cerri et al., 2008). Possivelmente, o comportamento pseudoplástico do caldo se deve à filamentação das células (Figura 3), que, segundo Jeong e Lee (2003), está relacionada à superexpressão de proteínas recombinantes. Considerando o erro padrão associado às estimativas de $\mu_{\text {ap }}$ verifica-se que este parâmetro não sofre alteração no decorrer da fase de indução. Portanto, pode-se afirmar que o crescimento celular e a síntese da proteína recombinante durante a fase de indução não afetam a viscosidade do caldo de cultivo e, de acordo com Cerri et al. (2008), a transferência de 
oxigênio.

\section{CONCLUSÕES}

Através dos resultados obtidos, comprovou-se que a elevação da pressão é uma forma promissora de controlar a COD em biorreator airlift de cilindros concêntricos. A pressurização do reator melhorou a transferência de oxigênio, possibilitando uma menor redução da temperatura no controle da COD, em relação ao cultivo sem sobrepressão, o que proporcionou aumentos de 2,2 e 9,6 vezes nas produtividades de biomassa e proteína recombinante (PspA), respectivamente.

Foi possível também constatar que a reologia do caldo de cultivo permaneceu praticamente inalterada durante a fase de indução, para a faixa de concentrações celulares estudadas e nas condições de indução empregadas. Isso significa que, mesmo com a superexpressão da proteína recombinante PspA, o efeito do aumento da concentração celular até $30 \mathrm{gMS} / \mathrm{L}$ é praticamente irrelevante para a viscosidade do caldo e a velocidade de transferência de oxigênio.

O desenvolvimento de um ambiente de cultivo baseado no biorreator airlift adaptado para operar em sobrepressão é igualmente útil em cultivos de outros microrganismos, contribuindo para o desenvolvimento de bioprocessos de um modo geral. A elaboração futura de um sistema robusto de controle da COD envolvendo pressões superiores proporcionariam produtividades ainda maiores no biorreator airlift.

\section{AGRADECIMENTOS:}

Beneficiário de auxílio financeiro da CAPES (Brasil) e da FAPESP (Brasil).

\section{REFERÊNCIAS}

BADINO, A. C.; HOKKA, C. O.; CERRI, M. O. Biorreator pneumático de circulação interna e uso do mesmo. BR n. PI 0404703-6, 2004.

CAMPANI, G. Reator airlift operado em sobrepressão: construção, caracterização da transferência de oxigênio e aplicação em cultivos de Escherichia coli recombinante. 2014. 101 f. Dissertação (Mestrado em Engenharia Química) - Departamento de Engenharia Química, Universidade Federal de São Carlos, São Carlos, 2014.

CAMPANI, G.; SILVA, G. G.; BADINO, A. C.; GIORDANO, R. C.; ZANGIROLAMI, T. C.; HORTA, A. C. L. Análise de variáveis para controle da concentração de oxigênio dissolvido em biorreator airlift. In: SIMPÓSIO NACIONAL DE BIOPROCESSOS, 19., 2013, Foz do Iguaçu. Anais... 1 DVD.

CERRI, M. O.; FUTIWAKI, L.; JESUS, C. D. F.; CRUZ, A. J. G.; BADINO, A. C. Average shear rate for non-Newtonian fluids in a concentric-tube airlift bioreactor. Biochemical Engineering Journal, v. 39, p. 51-57, 2008.

DEMAIN, A. L.; VAISHNAV, P. Production of recombinant proteins by microbes and higher organisms. Biotechnology Advances, v. 27, p. 297-306, 2009.

GLAZYRINA, J.; MATERNE, E. M.; DREHER, T.; STORM, D.; JUNNE, S.; ADAMS, T.; 
GRELLER, G.; NEUBAUER, P. High cell density cultivation and recombinant protein production with Escherichia coli in a rocking-motion-type bioreactor. Microbial Cell Factories, v. 9, p. 1-11, 2010.

HORTA, A. C. L. H. Sistema automático de supervisão e controle de cultivos de alta densidade celular de E. coli recombinante. 2009. 170 f. Tese (Doutorado em Engenharia Química) - Departamento de Engenharia Química, Universidade Federal de São Carlos, São Carlos, 2011.

JANARDHAN, S.; PANDIARAJA, P.; THIRUGNANAM, S.; BALAMURALI, M. N.; FERNANDO, K.; MODY, H. C.; DESAI, P. K.; MEENAKSHISUNDARAM, S.; KALIRAJ, P. Production, purification and diagnostic application of filarial recombinant protein WbSXP-1 expressed in salt inducible Escherichia coli. Journal of Industrial Microbiology and Biotechnology, v. 34, n. 10, p. 675-683, 2007.

JEONG, K. J.; LEE, S. Y. Enhanced production of recombinant proteins in Escherichia coli by filamentation suppression. Applied and Environmental Microbiology, v. 69, n. 2, p. 1295-1298, 2003.

KRACKE-HELMET, H. A.; RINAS, U.; HITZMANN, B.; SHÜGERL, K. Cultivation of recombinant Escherichia coli and production of fusion in 60-L bubble column and airlift tower loop reactors. Enzyme Microbiology Technology, v.13, p.554-564, 1991.

KORZ, D. J.; RINAS, U.; HELLMUTH, K.; SANDERS, E. A.; DECKWER, W. D. Simple fed-batch technique for high cell density cultivation of Escherichia coli. Journal of Biotechnology, v. 39, p. 59-65, 1995.

KYLE, S.; JAMES, K. A. R.; MCPHERSON, M. J. Recombinant production of the therapeutic peptide lunasin. Microbial Cell Factories, v. 11, n. 28, p. 1-8, 2012.

MARQUARDT, D. W. An algorithm for least-squares estimation of nonlinear parameters. Journal of the Society for Industrial and Applied Mathematics, v. 11, n. 2, p. 431-441, 1963.

SANTOS, M. P. Avaliação da temperatura de indução e de fontes de nitrogênio na produção de proteína de superfície de Streptococcus pneumoniae em Escherichia coli recombinante. 2012. 106 f. Dissertação (Mestrado em Engenharia Química) Departamento de Engenharia Química, Universidade Federal de São Carlos, São Carlos, 2012.

SHILOACH, J.; FASS, R. Growing Escherichia coli to high cell density: a historical perspective on method development. Biotechnology Advances, v. 23, p. 345-357, 2005.

SILVA, A. J.; HORTA, A. C. L.; VELEZ, A. M.; IEMMA, M. R. C.; SARGO, C. R.; GIORDANO, R. L. C.; NOVO, M. T. M.; GIORDANO, R. C.; ZANGIROLAMI, T. C. Non-conventional induction strategies for production of subunit swine erysipelas vaccine antigen in $\mathrm{r}$. coli fed-batch cultures. SpringerPlus, v. 2, p. 322, 2013.

STUDIER, F.W. Protein production by auto-induction in high-density shaking culture. Protein Expression and Purification, v.41, p. 313-322, 2005.

VOJINOVIC, V.; CABRAL, J. M. S.; FONSECA, L. P. Real-time bioprocess monitoring Part I: In situ sensors. Sensors and Actuators B, v. 114, p. 1083-1091, 2006. 